\title{
Modeling and Second Law Based Optimization of Plate Fin and Tube Heat Exchanger Using MOPSO
}

Ehsan Khorasani Nejad ${ }^{1}$, Mohsen Hajabdollahi ${ }^{2}$ and Hassan Hajabdollahi ${ }^{3 *}$

${ }^{1}$ Department of Mechanical Engineering, Behbahan Branch, Islamic Azad University, Behbahan, Iran

${ }^{2}$ Department of Computer Engineering, University of Isfahan, Isfahan, Iran

${ }^{3}$ Department of Mechanical Engineering, Vali-e-Asr University of Rafsanjan, Rafsanjan, Iran

\begin{abstract}
In the present study, a comprehensive thermal modeling and optimal design of plain Fin-and-Tube Heat Exchanger (FTHE) is performed. Hence, method is applied to estimate the heat exchanger pressure drop and effectiveness. The design parameters of this scientific study are selected as: longitudinal pitch, transversal pitch, fin pitch, number of tube pass, tube diameter, cold stream flow length, no-flow length and hot stream flow length. In addition, Multi Objective Particle Swarm Optimization (MOPSO) is applied to obtain the minimum number of entropy generation units and total annual cost (sum of investment and operation costs) as two objective functions, simultaneously. The results of optimal designs are a set of multiple optimum solutions, called 'Pareto optimal solutions'. It reveals that any geometrical changes which decrease the number of entropy generation units lead to an increase in the total annual cost and vice versa. Moreover, for prediction of the optimal design of the FTHE, an equation for number of entropy generation units versus the total annual cost is derived for the Pareto front. Furthermore, the sensitivity analysis of change in optimum number of entropy generation units and total annual cost with changes in design parameters of the fin tube heat exchanger is also performed in detail.
\end{abstract}

Keywords: Fin and tube heat exchanger; Number of entropy generation units; Annual cost; Objective function; MOPSO

\section{Nomenclature}

$A_{\text {flow }}$ minimum free-flow area on the tube outside $\left(m^{2}\right)$

$A_{\text {front }}$ frontal area $\left(m^{2}\right)$

$A$ heat transfer surface area $\left(m^{2}\right)$

$P_{f}$ fin $\operatorname{pitch}(m)$

$C_{\max }$ minimum of $\mathrm{Ch}$ and $\mathrm{Cc}(W / K)$

$C_{\max }$ maximum of $\mathrm{Ch}$ and $\mathrm{Cc}(W / K)$

$C^{*}$ heat capacity rate ratio $\left(\mathrm{C}_{\max } / \mathrm{C}_{\min }\right)$

$C_{i n v}$ annual cost of investment (\$/year)

$C_{\text {ope }}$ annual cost of operation (\$/year)

$C_{\text {tot }}$ total annual cost $(\$ /$ year $)$

$d_{i}$ tube inside diameter $(m)$

$d_{o}$ tube outside diameter $(m)$

$d_{e}$ fin collar outside diameter $(m)$

$D_{h}$ hydraulic diameter $(m)$

$F$ friction factor (-)

$G$ mass flux $\left(\mathrm{kg} / \mathrm{m}^{2} \mathrm{~s}\right)$

$h$ heat transfer coefficient $\left(W / M^{2} k\right)$

j Culburn number (-)

$K_{e l}$ price of electrical energy $\left(\$ M W h^{-1}\right)$

$L_{1}$ cold stream flow length $(m)$

$L_{2}$ hot stream flow length $(m)$

$L_{3}$ no-flow length $(m)$ $n$ exponent of nonlinear increase with area increase

$\mathrm{Nu}$ nusselt number (-)

NP number of tube passes (-)

$N_{r}$ number of tube row (-)

NS number of entropy generation units

$N_{t}$ total number of tube (-)

$N_{l}$ number of plate in $L_{1}$ direction (-)

NTU number of transfer units (-)

Pr Prandtl number (-)

$r$ interest rate (-)

Re Reynolds number (-)

St Stanton number (-)

$S$ rate of entropy generation $(W / K)$

$U$ overall heat transfer coefficient $\left(W / M^{2} k\right)$

$V$ heat exchanger volume $\left(m^{3}\right)$

$V_{t}$ volumetric flow rate $\left(\mathrm{m}^{3} / \mathrm{s}\right)$

$X_{l}$ longitudinal pitch $(m)$

*Corresponding author: Hassan Hajabdollahi, Department of Mechanica Engineering, Vali-e-Asr University of Rafsanjan, Rafsanjan, Iran, E-mail: Hassan.Hajabdollahi@gmail.com

Received December 20, 2012; Accepted January 28, 2013; Published February 02, 2013

Citation: Nejad EK, Hajabdollahi M, Hajabdollahi H (2013) Modeling and Second Law Based Optimization of Plate Fin and Tube Heat Exchanger Using MOPSO. J Appl Mech Eng 2: 118 doi:10.4172/2168-9873.1000118

Copyright: (C) 2013 Nejad EK, et al. This is an open-access article distributed under the terms of the Creative Commons Attribution License, which permits unrestricted use, distribution, and reproduction in any medium, provided the original author and source are credited. 


\section{$X_{t}$ transversal pitch $(m)$}

$y$ depreciation time (year)

Greek abbreviation

$\delta$ fin thickness $(m)$

$\varepsilon$ thermal effectiveness (-)

$\lambda$ nondimensional conduction parameter (-)

$\tau$ hours of operation per year

$\eta_{s}$ overall surface efficiency (-)

$\eta_{f}$ fin efficiency (-)

$\eta$ compressor efficiency (-)

$\mu$ viscosity (pa.s)

$V$ specific volume $\left(M^{3} / \mathrm{kg}\right)$

$\triangle P$ pressure drop $(\mathrm{Pa})$

$\sigma$ ratio between $A_{\text {flow }}$ and $A_{\text {front }}\left(A_{\text {flow }} / A_{\text {front }}\right)$

Subscripts

$f$ fin

$c$ cold

$i$ inside

In inlet

$o$ outside

out outlet

ave average

$h$ hot

tot total

\section{Introduction}

Compact heat exchangers are characterized by a large heat transfer surface area per unit volume of the exchanger. Fin Tube Heat Exchanger (FTHE) as shown in Figure 1, is a typical compact heat exchanger that

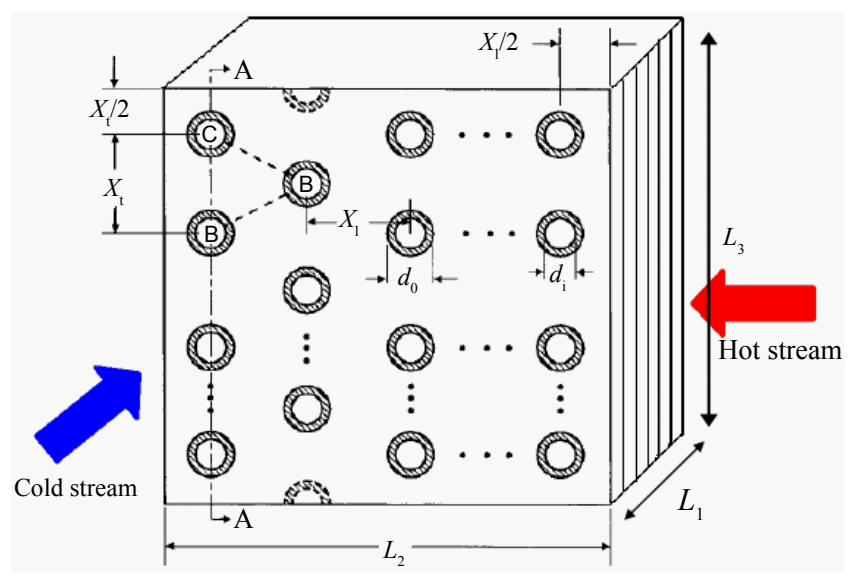

Figure 1: Typical plain fin and tube heat exchanger with staggered tube arrangement. is widely used in many industrial power generation plants, chemical, petrochemical, and petroleum industries. Fins or extended surface elements are introduced to increase the heat transfer area [1]. Some of commonly used fins are, wavy, offset strip, louver, perforated, and plain fins [2]. Recently, evolutionary algorithms have received a lot of attention as an optimization method particularly in heat exchanger design. Sanaye and Hajabdollahi applied NSGA-II and optimized the rotary regenerator, plate fin and shell and tube heat exchangers [3-5]. Dincer et al. obtained optimum cooling water temperature during condensation of saturated water vapor within a shell and tube condenser [6]. Hilbert et al. also, used a multi objective optimization technique to maximize the heat transfer rate and to minimize the pressure drop in a tube bank heat exchanger [7]. Xie et al. minimized the total volume as well as the total annual cost of a compact heat exchanger by considering three shape parameters as decision variables [8]. Wang et al. applied genetic algorithm to optimize primary energy saving, annual total cost saving, and carbon dioxide emission reduction [9]. Guo et al. employed genetic algorithm to optimize the field synergy number which is defined as the indicator of the synergy between the velocity field and the heat flow [10]. Sahin et al. optimized the design parameters of a heat exchanger with rectangular fins by Taguchi experimental-design method [11]. Doodman et al. minimized the total annual cost of air cooled heat exchangers using global sensitivity analysis [12]. Foli et al. estimated the optimum geometric parameters of micro channels in micro heat exchangers by maximizing the heat transfer rate and minimizing the pressure drop as two objective functions [13]. Liu and Cheng optimized a recuperator for the maximum heat transfer effectiveness as well as minimum exchanger weight and pressure loss [14]. Gholap and Khan also studied air cooled heat exchangers by minimizing the energy consumption of fans and material cost as two objective functions [15].

In this paper, it is aimed to first conduct a thermal modeling of a FTHE and later optimize this equipment by minimizing the number of entropy generation units as well as minimizing the total annual cost, simultaneously. Particle swarm optimization technique is applied to provide a set of the Pareto multiple optimum solutions. The sensitivity analysis of change in optimum values of number of entropy generation units and total annual cost with change in design parameters was performed and the results are reported. In summary, the following are the specific contributions of this paper to the area:

\section{Thermal modeling of a plain type fin tube heat exchanger}

Applying multi-objective optimization for fin and tube heat exchanger with number of entropy generation units and total annual cost as two objectives using particle swarm optimization algorithm.

Selecting the longitudinal pitch, transversal pitch, fin pitch, number of tube pass, tube diameter, cold stream flow length, no-flow length and hot stream flow length as design parameters (decision variables).

Proposing a closed form equation for the total annual cost in term of number of entropy generation units at the optimal design point.

Performing sensitivity analysis of change in objective functions when the optimum design parameters vary and find the degree of each parameter on objective functions conflicting.

\section{Thermal modeling}

The $\varepsilon-N T U$ method is applied here for predicting the heat exchanger performance. The effectiveness of cross-flow heat exchanger with both fluids unmixed is proposed as [16]: 


$$
\begin{aligned}
& \varepsilon=1-\exp \left[-\left(1+C^{*}\right) N T U\right] \times\left[I_{0}\left(2 N T U \sqrt{C^{*}}\right)+\right. \\
& \left.\sqrt{C^{*}} I_{1}\left(2 N T U \sqrt{C^{*}}\right)-\frac{1-C^{*}}{C^{*}} \sum_{n=2}^{\infty} C^{* n / 2} I_{n}\left(2 N T U \sqrt{C^{*}}\right)\right]
\end{aligned}
$$

Where $I$ is the modified Bessel function. Number of Transfer Units $(\mathrm{NTU})$ and heat capacity ratio $\left(C^{*}\right)$ are defined as follows [1]:

$$
\begin{aligned}
& N T U_{\max }=\frac{U_{o} A_{\text {tot }, h}}{C_{\text {min }}} \\
& \mathrm{C}^{\star}=\mathrm{C}_{\text {max }} / \mathrm{C}_{\text {min }}
\end{aligned}
$$

Here, $U_{o}$ is the overall heat transfer coefficient based on fin side, computed from:

$$
U_{o}=\frac{1}{\frac{1}{h_{h} \eta_{s, h}}+\frac{1}{\frac{A_{i, c}}{A_{t o t, h}}\left(h_{c} \eta_{s, c}\right)}}
$$

The fouling resistance and wall conduction resistance have been assumed to be negligible. Hear the $A_{i, c}$ is the total heat transfer area in inside of tube and $A_{t o t, h}$ is outside total heat transfer surface area including fins and tubes as follow:

$$
A_{\text {tot }, h}=A_{f}+A_{o, c}
$$

where $A_{f}$ and $A_{O, c}$ are the heat transfer surface area of fins and tube outside respectively as follow [17]:

$$
\begin{aligned}
& A_{f}=2 L_{1} / p_{f}\left(L_{2} \times L_{3}-N_{t} \times \pi d_{o}^{2} / 4\right) \\
& A_{o, c}=\pi d_{o} N_{t} L_{1}-N_{t} \times \pi d_{o} \delta\left(N_{1}-1\right)
\end{aligned}
$$

where $N_{t}$ and $N_{l}$ are the total tube number and the number of plate in $L_{1}$ direction. $h$ is the heat transfer coefficient, $\delta$ is the fin thickness and $L_{1}, L_{2}$ and $L_{3}$ are cold stream flow length, hot stream flow length and no-flow length, respectively (Figure 1).

Also $\eta_{s}$ in Equation 4 is overall surface efficiency defined as [1]:

$$
\eta_{s}=1-\frac{A_{f}}{A_{t o t, h}}\left(1-\eta_{f}\right)
$$

and $\eta_{f}$ is efficiency of a single fin.

The Fanning factor $f$ and Colburn factor $j$ (respectively representative of pressure drop and thermal performance) defined in Equations (9) and (10) by Wang et al [18] for plain flat fins on staggered tube banks as:

$$
\begin{aligned}
& j=\left\{\begin{array}{lr}
0.108 \operatorname{Re}_{d c}^{-0.29}\left(X_{t} / X_{l}\right)^{c_{1}}\left(p_{f} / d_{c}\right)^{-1.084}\left(p_{f} / D_{h}\right)^{-0.786}\left(p_{f} / X_{t}\right)^{c_{2}} & \text { for } N_{r}=1 \\
0.086 \operatorname{Re}_{d c}^{c_{3}} \cdot N_{r}^{c_{4}}\left(p_{f} / d_{c}\right)^{c_{5}}\left(p_{f} / D_{h}\right)^{c_{6}}\left(p_{f} / X_{t}\right)^{-0.93} & \text { for } N_{r} \geq 2
\end{array}\right. \\
& f=0.0267 \operatorname{Re}_{d c}^{c_{7}}\left(X_{t} / X_{l}\right)^{c_{8}}\left(p_{f} / d_{c}\right)^{c_{9}}
\end{aligned}
$$

where

$$
\begin{aligned}
& c_{1}=1.9-0.23 \ln \operatorname{Re}_{d c} \\
& c_{2}=-0.236+\ln \operatorname{Re}_{d c} \\
& c_{3}=-0.361-\frac{0.042 N_{r}}{\ln \operatorname{Re}_{d c}}+0.158 \ln \left[N_{r}\left(p_{f} / d_{c}\right)^{0.41}\right] \\
& c_{4}=-1.224-\frac{0.076\left(X_{l} / D_{h}\right)^{1.42}}{\ln \operatorname{Re}_{d c}} \\
& c_{5}=-0.083+\frac{0.058 N_{r}}{\ln \operatorname{Re}_{d c}} \\
& c_{6}=-5.735+1.21 \ln \frac{\operatorname{Re}_{d c}}{N_{r}} \\
& c_{7}=-0.764+0.739\left(X_{t} / X_{l}\right)+0.177\left(p_{f} / d_{c}\right)-0.00758 / N_{r} \\
& c_{8}=-15.689+64.021 / \ln \operatorname{Re}_{d c} \\
& c_{9}=1.696-15.695 / \ln \operatorname{Re}_{d c}
\end{aligned}
$$

The above equations are valid for $300<\operatorname{Re}<20000$ and for $6.9 \leq d_{c} \leq 13.6 \mathrm{~mm}, \quad 1.3 \leq D_{h} \leq 9.37 \mathrm{~mm}, \quad 20.4 \leq X_{t} \leq 31.8 \mathrm{~mm}, \quad 12.7 \leq X_{l} \leq 32 \mathrm{~mm}$, $1.0 \leq p_{f} \leq 8.7 \mathrm{~mm}$ and $1 \leq N_{r} \leq 6$. The proposed correlations for Colburn number and fanning friction factor are accurate within $\pm 15 \%$ [18]

The Reynolds number and hydraulic diameter are defined as [18]:

$$
\operatorname{Re}_{d c}=\frac{G d_{c}}{\mu}
$$

where

$$
d_{c}=d_{o}+2 \delta
$$

and $G$ is mass flux.

The heat transfer coefficient is defined as follow [1]:

$$
h=S t G c_{p}
$$

where $S t$ is Stanton number defined as:

$$
S t=\frac{j}{\operatorname{Pr}^{2 / 3}}
$$

Furthermore, the pressure drop was also estimated from [1]:

$$
\Delta P=G^{2} v_{\text {in }} / 2\left[\left(1+\sigma^{2}\right)\left(v_{\text {out }} / v_{\text {in }}-1\right)+f \frac{A_{\text {tot }}}{A_{\text {flow }}} \frac{v_{\text {ave }}}{v_{\text {in }}}\right]
$$

where $A_{\text {flow }}$ minimum free-flow area on the tube outside.

The number of entropy generation units is defined as follows [19]:

$$
N S=\frac{\dot{S}}{C_{\max }}
$$

where $\dot{S}$ is the rate of entropy generation:

$$
\dot{S}=\Delta S_{c}+\Delta S_{h}
$$

and:

$$
\Delta S=\dot{m}\left[c_{p} \ln \frac{T_{\text {out }}}{T_{\text {in }}}-R \ln \frac{P_{\text {out }}}{P_{\text {in }}}\right]
$$

\section{Influence of longitudinal heat conduction}

To evaluate the influence of heat conduction in the flow direction either in the solid wall or in the fluid, the following approximation for longitudinal conduction analysis has been also performed. Fluids 
generally have a low thermal conductivity (liquid metal excepted), but the wall conductivity may be quite high. Consequently, only wallconduction effects will be considered in the following treatment. The influence of longitudinal conduction is to reduce exchanger effectiveness for a given number of transfer units, and this reduction may be quiet serious in exchangers with short flow lengths design for high effectiveness values $(\varepsilon>90 \%)$ [1]. Assuming the temperature difference $\delta T$ for the hot fluid, is of the same magnitude for the cold fluid $\left(C_{\min } / C_{\max } \approx 1\right)$, and also for the wall then the wall temperature gradient is $\delta T / L$, with $L$ being the flow length and the longitudinal heat transfer by conduction is of the order [1]. If the wall cross-section area for longitudinal conduction is designated $A_{k}$ :

$$
q_{\text {cond }} \approx k_{w} A_{k} \frac{\delta T}{L}
$$

where $A_{k}$, is the wall cross-section area for longitudinal conduction and $k_{w}$, is the wall conduction coefficient.

The convection heat transfer rate is also given by energy-balance considerations as:

$$
q_{\text {conv }}=C_{c} \delta T=C_{h} \delta T
$$

and then:

$$
\frac{q_{\text {cond }}}{q_{\text {conv }}}=\frac{\left(k_{w} / L\right) A_{k}}{C}=\frac{\left(k_{w} / L\right) A_{f r}(1-\sigma)}{C_{\min }}=\lambda
$$

where $\lambda$ in equation 22 , is the nondimensional conduction parameter. The values of $\lambda$ are computed for various optimal design points as presented in the case study.

\section{Particle Swarm for multi-objective optimization}

Multi-objective optimization: A multi-objective problem consists of optimizing (i.e. minimizing or maximizing) several objectives simultaneously with a number of inequality or equality constraints. The problem can be formally written as follows:

Find $x=\left(x_{i}\right) \forall i=1,2, \ldots, N_{\text {param }}$ such as

$f_{i}(x)$ minimized or maximized $\forall i=1,2, \ldots, N_{o b j}$

Subject to:

$$
\begin{aligned}
& g_{j}(x)=0 \quad \forall j=1,2, \ldots, M, \\
& h_{k}(x) \leq 0 \quad \forall k=1,2, \ldots, K,
\end{aligned}
$$

where $x$ is a vector containing $N_{\text {param }}$ design parameters, $\left(f_{i}\right)_{i=1, \ldots ., N o b j}$ are objective functions and $N_{o b j}$ is the number of objectives. Objective functions $\left(f_{i}\right)_{i=1, \ldots, N o b j}$ return a vector containing the set of $N_{o b j}$ values associated with the elementary objectives to be optimized simultaneously. The concept of Particle Swarm Optimization (PSO) is inspired by the flocking behavior of the birds. It was first proposed by Kennedy in 1995 [20]. Like evolutionary algorithms PSO is also a population based heuristic, where the population of the potential solutions is called a swarm and each individual solution within the swarm, is called a particle. There have been several recent attempts to use PSO for Multi-Objective Optimization (MOO) [21-23]. This algorithm is called Multi-Objective Particle Swarm Optimization Algorithm (MOPSOA) which is coupled with the objective functions developed in this study for optimization.
Velocity and position updating: The movement of the particle towards the optimum solution is governed by updating its position and velocity attributes. The velocity and position update equations are given as [20]:

$$
\begin{aligned}
& v_{k+1}^{i}=w v_{k}^{i}+c_{1} \operatorname{rand}\left(p^{i}-x_{k}^{i}\right)+c_{2} \operatorname{rand}\left(p_{k}^{g}-x_{k}^{i}\right) \\
& x_{k+1}^{i}=x_{k}^{i}+v_{k+1}^{i}
\end{aligned}
$$

where $i$ represents the $i$ th particle in the population and $k$ represents each iteration.

The term $p_{k}^{g}$ specifies the best global solution obtained by the swarm and $p^{i}$ is the best position of each particle over time. In addition $w, c_{1}$ and $c_{2}$ are the inertia weight, self confidence factor and swarm confidence factor respectively and rand is the random number generated uniformly in the range [0-1].

Best position of each particle $\left(p^{i}\right)$ : In MOPSOA the individual experience of the particle is captured, that corresponds to the best performance attained so far by it in its flight. Actually the present solution is compared with the previous solutions, and it replaces the latter only if it dominates that solution. If neither of them is dominated by the other, then one of them is selected randomly [21].

Best global position of swarm $\left(p_{k}^{g}\right)$ : The term $p_{k}^{g}$ represents the best solution obtained by the swarm. Often the conflicting nature of the multiple objectives involved in MOO problems makes the choice of a single optimum solution difficult. To resolve this problem, the concept of non-dominance is used and an archive of non-dominated solutions is maintained, from which a solution is picked up as the $p_{k}^{g}$. The selection of the $p_{k}^{g}$ solution is done from the archive on the basis of the diversity of the solutions. In MOPSOA the diversity measurement has been done using a concept similar to the crowding-distance measure in [24].

Crowding distance: The standard crowding distance proposed by Deb [24] is utilized, where the crowding distance of an individual is the perimeter of the rectangle with its nearest neighbors at diagonally opposite corners. So, if two individuals have the same rank, each one who has a larger crowding distance is better.

Historical Archive: The MOPSOA algorithm has been modified to include an archive of the historically non-dominated individuals. Archive is used to update the data at each iteration.

\section{Objective Functions, Design Parameters and Constraints}

In this study, number of entropy generation units (defined in Equation 17) and total annual cost are considered as two objective functions. Total annual cost is includes investment cost (the annualized cost of the heat transfer surface area) and operating cost of compressor/ pump to flow the fluid as follows [8]:

$$
\begin{aligned}
& C_{\text {tot }}=a C_{\text {inv }}+C_{\text {ope }} \\
& C_{\text {inv }}=C_{A} \times A_{\text {tot }}^{n} \\
& C_{\text {ope }}=\left(k_{\text {el }} \tau \frac{\Delta p V_{t}}{\eta}\right)_{c}+\left(k_{e l} \tau \frac{\Delta p V_{t}}{\eta}\right)_{h}
\end{aligned}
$$

Here $C_{A}$ and $K_{e l}$ are the heat exchanger investment cost per unit surface area and the electricity unit cost respectively, $n$ is a constant and $\tau$ is the operation hours of the exchanger per year. $\Delta p, V_{t}$ and $\eta$ are pressure drop, volume flow rate and compressor efficiency, respectively. 
Citation: Nejad EK, Hajabdollahi M, Hajabdollahi H (2013) Modeling and Second Law Based Optimization of Plate Fin and Tube Heat Exchanger Using MOPSO. J Appl Mech Eng 2: 118 doi:10.4172/2168-9873.1000118

Also $a$ is annual cost coefficient defined as:

$$
a=\frac{r}{1-(1+r)^{-y}}
$$

where $r$ and $y$ are interest rate and depreciation time respectively. In this study longitudinal pitch $\left(X_{l}\right)$, transversal pitch $\left(X_{t}\right)$, fin pitch $\left(P_{f}\right)$, number of tube pass $(N P)$, outside tube diameter $\left(d_{0}\right)$, cold stream flow length $\left(L_{1}\right)$, no-flow length $\left(L_{3}\right)$ and hot stream flow length $\left(L_{2}\right)$ were considered as eight design parameters. The constrains are introduced to insure that the $d_{c}, D_{h}, X_{t}, X_{l, p_{f}}$ and $N_{r}$ are in the range of $\quad 6.9 \leq d_{c} \leq 13.6 \mathrm{~mm}, \quad 1.3 \leq D_{h} \leq 9.37 \mathrm{~mm}, \quad 20.4 \leq X_{t} \leq 31.8 \mathrm{~mm}$, $12.7 \leq X_{l} \leq 32 \mathrm{~mm}, \quad 1.0 \leq p_{f} \leq 8.7 \mathrm{~mm}, 2 \leq N_{r} \leq 6$ and $300<\operatorname{Re}<20000$.

\section{Case Study}

In this part, our case study has been considered. Outlet gases from the compressor with mass flow rate $2.5 \mathrm{~kg} / \mathrm{s}$ and temperature $425 \mathrm{~K}$ enters the fin tube pre-cooler heat exchanger. On the other hand, water with $3.2 \mathrm{~kg} / \mathrm{s}$ and temperature $285 \mathrm{~K}$ flow in the other side. The FTHE metal is made of stainless steel with thermal conductivity about $k_{w}=25$ $W / m . K$. Also, the ratio of inside to outside tube diameter is taken to be 0.8 . Operating conditions and the cost function constant values are listed in Table 1. The thermophysical properties of air such as Prandtl number, viscosity and specific heat were considered as temperature dependent.

\section{Discussion and Results}

\section{Longitudinal heat conduction}

To quantify the effect of longitudinal heat conduction in comparison with the convection heat transfer, the numerical values of $\lambda$ (equation 22) were computed for $k_{w}=25 \mathrm{~W} / \mathrm{m} . \mathrm{k}$ for all optimum design cases as is shown in Figure 2. It was found that the distribution of $\lambda$ value in the whole optimal output domain show the numerical values less than $0.005(0.5 \%)$. This shows that assuming the negligible conduction heat transfer in our analysis in flow direction is acceptable for the studied problem.

\section{Verification of modeling and optimization results}

To verify the modeling results, the simulation output were compared with the corresponding reported results given in reference [1]. The comparison of our modeling results and the corresponding values from reference [1], for the same input values listed in Table 2, are given in Table 3 . The results show that the difference percentage points of two mentioned modeling output results are acceptable.

\section{Optimization results}

To minimize the number of entropy generation units and the total

\begin{tabular}{|l|c|}
\hline Mass flow rate of hot flow & 2.5 \\
\hline Mass flow rate of cold flow & 3.2 \\
\hline Inlet hot temperature & 425 \\
\hline Inlet cold temperature & 285 \\
\hline Inlet pressure (hot side) & 250 \\
\hline Inlet pressure (cold side) & 200 \\
\hline Price per unit area & 85 \\
\hline Exponent of nonlinear increase with area increase & 0.6 \\
\hline Hours of operation per year & 5000 \\
\hline Price of electrical energy & 25 \\
\hline Compressor or pump efficiency & 0.65 \\
\hline
\end{tabular}

Table 1: The operating conditions of the FTHE (input data for the model).

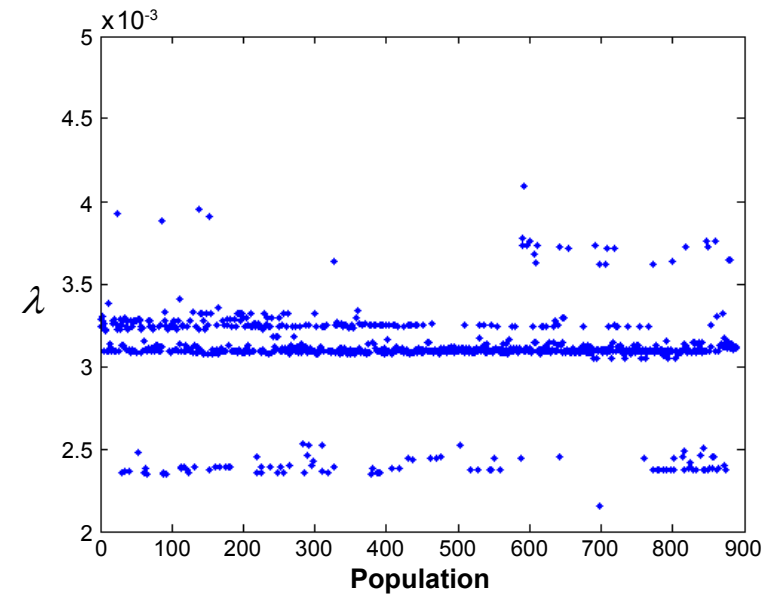

Figure 2: The distribution of numerical values of $\lambda$ (the non-dimensional heat conduction parameter) in the whole optimal output domain.

\begin{tabular}{|l|c|}
\hline Variables & Value \\
\hline Longitudinal pitch $(\mathrm{mm})$ & 22 \\
\hline Transversal pitch $(\mathrm{mm})$ & 25.4 \\
\hline Fin pitch $(\mathrm{mm})$ & 3.175 \\
\hline Outside tube diameter $(\mathrm{mm})$ & 10.2 \\
\hline Fin thickness $(\mathrm{mm})$ & 0.33 \\
\hline Reynolds number & 1968 \\
\hline
\end{tabular}

Table 2: Geometrical characteristic of plain fin and tube heat exchanger from references [1].

\begin{tabular}{|l|l|l|l|}
\hline Output variables & Ref.[1] & Present paper & Difference (\%) \\
\hline$D_{h}(\mathrm{~mm})$ & 3.632 & 3.368 & -7.26 \\
\hline$A_{\text {flow }} / A_{\text {front }}$ & 0.534 & 0.495 & -7.3 \\
\hline$A_{\text {tot }} / V\left(\mathrm{~m}^{2} / \mathrm{m}^{3}\right)$ & 587 & 587.76 & 0.13 \\
\hline$A_{h} / A_{\text {tot }}$ & 0.913 & 0.915 & 0.35 \\
\hline$j$ & 0.008 & 0.0091 & 13.75 \\
\hline$f$ & 0.0263 & 0.0299 & 13.68 \\
\hline
\end{tabular}

Table 3: The comparison of modeling output and the corresponding results from reference [1].

\begin{tabular}{|l|l|l|l|}
\hline Variables & From & To & Change step \\
\hline Longitudinal pitch $(\mathrm{mm})$ & 12.7 & 32 & 1 \\
\hline Transversal pitch $(\mathrm{mm})$ & 20.4 & 31.8 & 1 \\
\hline Fin pitch $(\mathrm{mm})$ & 1 & 8.7 & 1 \\
\hline Number of tube pass $(-)$ & 2 & 6 & 2 \\
\hline Outside tube diameter $(\mathrm{mm})$ & 7 & 10 & 1 \\
\hline Cold stream flow length $(\mathrm{m})$ & 0.2 & 1 & 0.001 \\
\hline No-flow length $(\mathrm{m})$ & 0.2 & 1 & 0.001 \\
\hline Hot stream flow length $(\mathrm{m})$ & 0.06 & 0.2 & 0.001 \\
\hline
\end{tabular}

Table 4: The design parameters, their range of variation and their change step.

annual cost, eight design parameters including longitudinal pitch, transversal pitch, fin pitch, number of tube pass, tube diameter, cold stream flow length, no-flow length and hot stream flow length were selected. Design parameters (decision variables) and the range of their variations are listed in Table 4 . The number of iterations for finding the global extremum in the whole searching domain was about $10^{25}$. System was optimized for depreciation time $y=12$ years and interest rate The 


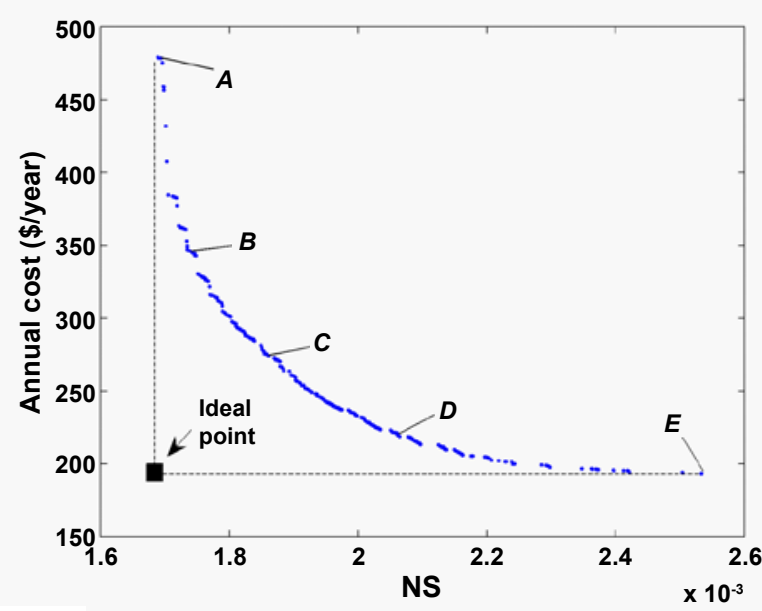

Figure 3: The distribution of Pareto-optimal points solutions using MOPSO

\begin{tabular}{|l|l|l|l|l|l|}
\hline & A & B & C & D & E \\
\hline $\begin{array}{l}\text { Number of entropy } \\
\text { generated units }\end{array}$ & $1694 \times 10^{-6}$ & $1739 \times 10^{-6}$ & $1861 \times 10^{-6}$ & $2064 \times 10^{-6}$ & $2533 \times 10^{-6}$ \\
\hline $\begin{array}{l}\text { Total Annual Cost } \\
\text { (\$/year) }\end{array}$ & 478.4 & 346.0 & 274.0 & 218.8 & 193.3 \\
\hline
\end{tabular}

Table 5: The optimum values of number of entropy generation units and the tota annual cost for the design points $A$ to $E$ in Pareto optimal front for input values given in table 1 .

particle swarm optimization was performed for 500 iterations, using 100 particles, inertia weight of $w=0.4$, self confidence factor of $c_{1}=1.75$ and swarm confidence factor $c_{2}=1.8$. The results for Pareto-optimal front are shown in Figure 3, which clearly reveal the conflict between two objectives, the number of entropy generation units and the total annual cost. Any geometrical change that decreases the number of entropy generation units, leads to an increase in the total annual cost and vice versa. This shows the need for multi-objective optimization techniques in optimal design of a FTHE. It is shown in Figure 3, that the minimum number of entropy generation units exists at design point $A(0.001694)$, while the total annual cost is the biggest at this point. On the other hand the minimum total annual cost occurs at design point $E$ (193.3 \$/year), with a biggest number of entropy generation units value $(0.002533)$ at that point. Design point $A$ is the optimal situation at which, number of entropy generation units is a single objective function while design point $E$ is the optimum condition at which total annual cost is a single objective function.

The optimum values of two objectives for five typical points from A to E (Pareto-optimal fronts) for input values are given in table 1 are listed in table 5 .

To provide a useful tool for the optimal design of the FTHE, the following equation for number of entropy generation units versus the total annual cost was derived for the Pareto curve (Figure 3).

$$
C_{\text {total }}(\$ / \text { year })=\frac{0.4425 N S^{3}-37.171 N S^{2}-1735 N S+52040}{N S^{2}-181.2 N S+3924} \times 100000
$$

which is valid in the range of $0.001694<\mathrm{NS}<0.002533$ for number of entropy generation units. The interesting point is that considering a numerical value for the number of entropy generation units in mentioned range, provides the minimum total annual cost for that optimal point along with other optimal design parameters.
The selection of a single optimum point from existing points on the Pareto front needs a process of decision-making. In fact, this process is mostly carried out based on engineering experiences and importance of each objective for decision makers. The process of final decisionmaking in Figure 3 is usually performed with the aid of a hypothetical point named as equilibrium point, that both objectives have their optimal values independent of the other objectives [25]. It is clear that it is impossible to have both objectives at their optimum point, simultaneously. The equilibrium point is not a solution located on the Pareto frontier. In this paper, LINMAP method was used to find the final optimum solution in Pareto front [25].

In the LINMAP method, each objective is non-dimensionalized using the following relation:

$$
F_{i j}^{n}=\frac{F_{i j}}{\sqrt[2]{\sum_{i=1}^{m}\left(F_{i j}\right)^{2}}}
$$

where $i$ is the index for each point on the Pareto frontier, $j$ is the index for each objective in the objectives space and $m$ denotes the number of points in the Pareto front. After non-dimensionalization of all objectives, the distance of each solution on the Pareto frontier from the ideal point obtained. The closest point of Pareto frontier to the equilibrium point (design point $D$ ) might be considered as a desirable final solution with the 0.002064 of number of entropy generation units and 218.8 \$hour as total annual cost rate.

The distribution of variables for the optimal points on Pareto front (Figure 3) is shown in Figures 4a to $4 \mathrm{~h}$. The lower and upper bounds of the variables are shown by dotted lines. The following points for the optimal variables in Figure 4 could be deduced:

i. The numerical values of the cold stream flow length and no flow length have the values relatively distributed in its lower domain.

ii. The other design parameters are almost constant for all optimum cases.

Since the optimum values of two decision variables (cold stream flow length and no flow length) have scattered distribution in their lower domains, one may predict that these two parameters have important effects on the conflict between the number of entropy generation units and total annual cost. The other six design parameters have no effect on the conflict between the two objective functions and improve both objective functions at a specific value. The variation of optimum value of number of entropy generation units with the total annual cost for various values of optimum design parameters in design point $\mathrm{D}$ (selected as final optimum design in Pareto front) are shown in Figures $5 \mathrm{a}$ to $5 \mathrm{~h}$. The effect of design variables on objective functions are investigated and explained as follows:

Cold stream flow length: Based on the information in Figure 5a, it is found that by increase in the cold stream flow length, number of entropy generation units is increased continuously and annual cost decreases. Therefore, this increment leads to conflicting behavior on objective functions. The relatively scattering distribution of optimal points in Figure 4a confirms this idea.

Hot stream flow length: As it is shown in Figure 5b, increasing the hot stream flow length results in increase in the both number of entropy generation units as well as total annual cost. Therefore, both objectives improve by decreases of hot stream flow length. The numerical value of hot stream flow length located at its minimum value in Figure $4 \mathrm{~b}$ verified this point. 

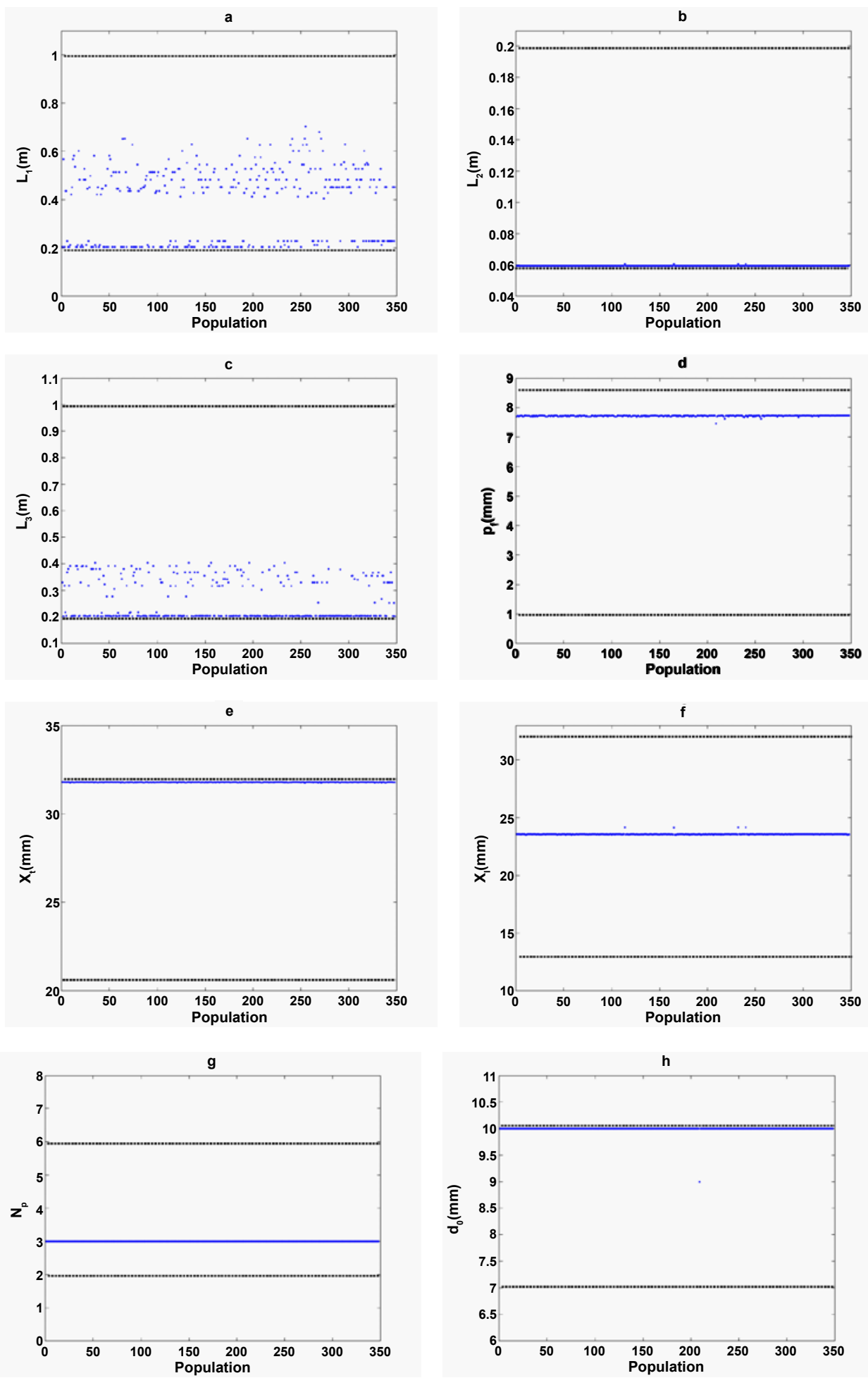

Figure 4: Scattering of variables for the Pareto optimal front a: cold stream flow length, b: hot stream flow length, c: no-flow length, d: fin pitch,e: transversal pitch, f: longitudinal pitch, $\mathbf{g}$ : number of tube pass, h: tube diameter.

No-flow length: Like hot stream flow length, by increase in the noflow length number of entropy generation units and annual cost increase simultaneously. But there is a small region in Figure $5 \mathrm{c}$ that causes conflict between two objectives. The relative scattering distribution of no-flow length in Figure $4 \mathrm{c}$ at its minimum values confirms this point.

Fin pitch, transversal pitch and longitudinal pitch: As shown 

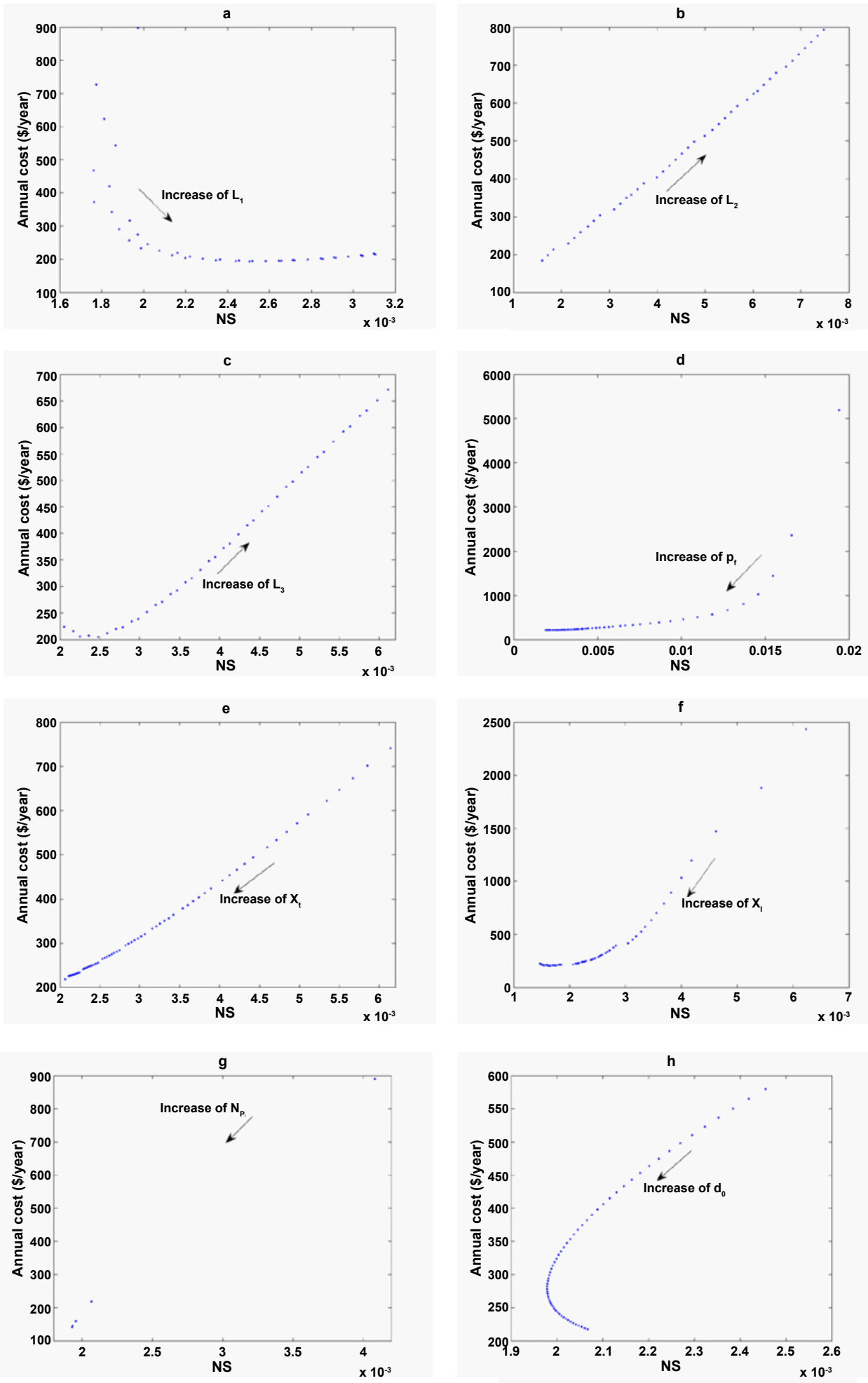

Figure 5: The variation of number of entropy generation units with annual cost for eight optimum design parameters in design point $D$. a: cold stream flow length, $\mathbf{b}$ : hot stream flow length, c: no-flow length, d: fin pitch e: transversal pitch, f: Longitudinal pitch, $\mathbf{g}$ : number of tube pass, $\mathbf{h}$ : tube diameter.

in Figures 5d- 5f, by increasing the fin pitch, transversal pitch and longitudinal pitch both the number of entropy generation units and annual cost improved simultaneously. As a result, the higher values of these three parameters are suitable (until it does not violence the constraints) for multi-objective optimization as shown in Figures $4 \mathrm{~d}$ 4f.

Number of tube pass: Based on Figure $5 \mathrm{~g}$, by increase of the tube 
Citation: Nejad EK, Hajabdollahi M, Hajabdollahi H (2013) Modeling and Second Law Based Optimization of Plate Fin and Tube Heat Exchanger Using MOPSO. J Appl Mech Eng 2: 118 doi:10.4172/2168-9873.1000118

passes, both the number of entropy generation units and annual cost decrease, simultaneously. Therefore, the higher value of this parameter is suitable until it does not violence the constraints. Hence, number 3 is selected for tube passes as shown in Figure 4g.

Tube diameter: As shown in Figure $5 \mathrm{~h}$ by increasing the tube diameter, both annual cost and number of entropy generation units decrease (except in a small region for number of entropy generation units). Selecting the maximum value for the tube diameter in Figure $4 \mathrm{~h}$ confirms this point.

\section{Conclusions}

In the present paper, thermal modeling of the plain fin and tube heat exchanger has been carried out. For this task, a fin tube heat exchanger is optimally designed using multi objective optimization technique. The design parameters (decision variables) are longitudinal pitch, transversal pitch, fin pitch, number of tube pass, tube diameter, cold stream flow length, no-flow length and hot stream flow length. In the presented optimization problem, the number of entropy generation units and total annual cost were two objective functions (both of them were minimized, simultaneously). A set of Pareto optimal front points were shown. Further, the distribution of each design parameters in their allowable range is shown. The results revealed the level of conflict between the two objectives. Furthermore the correlation between the optimal values of two objective functions is proposed. It is found that each point in the Pareto frontier would be a final optimized point which strongly depends on the decision maker. However, a decision making method based on LINMAP method was presented to specify the final optimum design. Finally, the cold stream flow length and no flow length are found to be important design parameters which caused a relative conflict between number of entropy generation units and the total annual cost. The results show that by decrease of hot stream flow length and by increase of fin pitch, transversal pitch, longitudinal pitch, number of tube pass and tube diameter, both the number of entropy generation units and annual cost improved, simultaneously.

\section{References}

1. Kays WM, London AL (1984) Compact Heat Exchangers. Mc-Graw Hill, New York, USA.

2. Kim B, Sohn B (2006) An experimental study of flow boiling in a rectangular channel with offset strip fins. Int J Heat Fluid FI 27: 514-521.

3. Sanaye S, Hajabdollahi H (2009) Multi-objective optimization of rotary regenerator using genetic algorithm. Int J Therm Sci 48: 1967-1977.

4. Sanaye S, Hajabdollahi $\mathrm{H}$ (2010) Thermal-economic multi-objective optimization of plate fin heat exchanger using genetic algorithm. Appl Energ 87: 1893-1902.

5. Sanaye S, Hajabdollahi $H(2010)$ Multi-objective optimization of shell and tube heat exchangers. Appl Therm Eng 30: 1937-1945.

6. Haseli Y, Dincer I, Naterer GF (2008) Optimum temperatures in a shell and tube condenser with respect to exergy. Int J Heat Mass Tran 51: 2462-2470.

7. Hilbert R, Janiga G, Baron R, Thevenin D (2006) Multi-objective shape optimization of a heat exchanger using parallel genetic algorithms. Int J Heat Mass Tran 49: 2567-2577.

8. Xie GN, Sunden B, Wang QW (2008) Optimization of compact heat exchangers by a genetic algorithm. Appl Therm Eng 28: 895-906.

9. Wang JJ, Jing YY, Zhang CF (2010) Optimization of capacity and operation for CCHP system by genetic algorithm. Appl Energ 87: 1325-1335.
10. Guo J, Xu M, Cheng L (2009) The application of field synergy number in shelland-tube heat exchanger optimization design. Appl Energ 86: 2079-2087.

11. Sahin B, Yakut K, Kotcioglu I, Celik C (2005) Optimum design parameters of a heat exchanger. Appl Energ 82: 90-106.

12. Doodman AR, Fesanghary M, Hosseini R (2009) A robust stochastic approach for design optimization of air cooled heat exchangers. Appl Energ 86: 12401245.

13. Foli K, Okabe T, Olhofer M, Jin Y, Sendhoff B (2006) Optimization of micro heat exchanger: CFD, analytical approach and multi-objective evolutionary algorithms. Int J Heat Mass Tran 49: 1090-1099.

14. Liu Z, Cheng $H$ (2008) Multi-objective optimization design analysis of primary surface recuperator for microturbines. Appl Therm Eng 28: 601-610.

15. Gholap AK, Khan JA (2007) Design and multi-objective optimization of heat exchangers for refrigerators. Appl Energ 84: 1226-1239.

16. Franco A, Giannini N (2005) Optimum thermal design of modular compact heat exchangers structure for heat recovery steam generators. Applied Thermal Engineering 25: 1293-1313.

17. Shah RK, Sekulic PD (203) Fundamental of Heat Exchanger Design. John Wiley \& Sons Inc.

18. Wang CC, Chi KU, Chang CJ (2000) Heat transfer and friction characteristics of plain fin-and-tube heat exchangers, part II: Correlation. Int J Heat Mass Trans 43: $2693-2700$.

19. Mishra M, Das PK, Sarangi S (2009) Second law based optimization of cross flow plate-fin heat exchanger design using genetic algorithm. App Thermal Eng 29: 2983-2989.

20. Kennedy J, Eberhart R (1995) Particle swarm optimization. IEEE Internationa Conference Neural Networks, USA.

21. Coello CAC, Pulido GT, Lechuga MS (2004) Handling multiple objectives with particle swarm optimization, IEEE Transactions on Evolutionary Computation 8: 256-279.

22. Mostaghim S, Teich J (2003) Strategies for Finding Good Local Guides in Multiobjective Particle Swarm Optimization. IEEE Service Center, Inidanapolis, Indiana, USA.

23. Ratnaweera A, Halgamuge SK, Watson HC (2004) Self-organizing hierarchical particle swarm optimizer with time-varying acceleration coefficients. IEEE Transactions On Evolutionary Computation 8: 240-255.

24. K. Deb, A. Pratap, S. Agarwal, T. Meyarivan, A fast and elitist multi-objective genetic algorithm: NSGA-II, IEEE Transactions On Evolutionary Computation 6: 182-97.

25. Yu PL. Multiple-Criteria decision making, concepts, Techniques, and Extensions. New York, Plenum Press. 